mas con la pintura gótica de aquí de finales del siglo Xv, mezclada con ciertos aspectos de la valenciana. En fecha reciente se ha hecho una edición facsímil de la obra y un estudio de las miniaturas por Ana Domínguez, quien opina se debe a un buen iluminador, que recuerda la miniatura francesa de finales del siglo XV y comienzos del XVI ${ }^{16}$. También creo, se deben añadir ciertas concordancias de las miniaturas de 1502 con las del Gradual, Pars Prior (Huesca, Museo Capitular), procedente del «scriptorium» del real monasterio de Santa Engracia de Zaragoza, que formaba parte de la espléndida colección de cantorales financiados en su mayoría por los Reyes Católicos ${ }^{17}$.

A pesar del interés suscitado por el Cancionero de Pedro Marcuello en los últimos tiempos, no resulta fácil llegar a una conclusión definitiva sobre el autor de las miniaturas porque, como escribe Joaquín Yarza, «la historia de la miniatura en tiempos de los Reyes Católicos está aún por hacer» ${ }^{18}$.

Carmen MORTE GARCÍA Universidad de Zaragoza

\title{
LA INFLUENCIA DE LOS GRABADOS EN LAS MINIATURAS DE LOS LIBROS DE CORO DE LA CATEDRAL DE SEVILLA
}

Las colecciones de grabados que circulaban por Europa divulgaron tipos y modelos que se usaron en todas las épocas, en todos los países y en todas las facetas del arte como recetas cómodas de seguir. Algunos trabajos han señalado el uso de estos grabados por parte de artistas españoles como los de Sentenach y Cabañas, Angulo Íñiguez o Lacarra Ducay ${ }^{1}$ centrándose en los de Schongauer. Sin embargo el tema es mucho más amplio pues la influencia de los grabados no se redujo a los de este autor, de indudable importancia, sino que se amplió con los de otros artistas nórdicos principalmente alemanes, como el Maestro E. S. o Israel van Meckenen, pero también de Países Bajos como el monogramista F. V. B. o Iam van Zwolle ${ }^{2}$.

${ }^{16}$ Pedro Marcuello, El rimado de la conquista de Granada o cancionero de Pedro Marcuello. Madrid, Edilán, 1995, edición facsímil íntegra del manuscrito. Publicado conjuntamente con la edición crítica por E. Ruiz- Gálvez Priego. Más un análisis de las miniaturas por A. Domínguez.

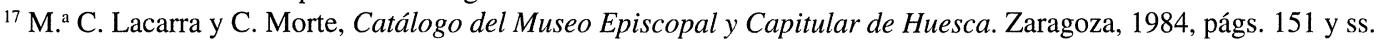

${ }^{18}$ J. Yarza, Los Reyes, págs. 63-85. Vid. del mismo autor, Los Reyes Católicos. Pasaje artístico de una monarquía. Madrid, Nerea, 1993.

${ }^{1}$ Sentenach y Cabañas, N., «Las tablas antiguas del Museo del Prado», Boletín de la Sociedad Española de Excursiones, 1900 , págs. 99 y ss.

Angulo Íñiguez, D., «Martín Shongauer y algunas miniaturas castellanas», Arte Español, VII, 1925, págs. 173-180.

«Gallego y Shongauer. La pintura en Burgos a principios del siglo XVI, nuevas huellas de Shongauer», Archivo Español de Arte y Arqueología, XVIII, 1930, págs. 74-77.

Lacarra Ducay, M. C., «Huella de Martín Shongauer en los primitivos aragoneses», Archivo Español de Arte, LII, 1979, págs. 347-350.

«Influencia de Martín Shongauer en los primitivos aragoneses», Boletín del Museo e Instituto Camón Aznar, XVII, 1984, págs. 15-39.

2 Silva Maroto, P., «Influencia de los grabados nórdicos en la pintura hispano-flamenca», Archivo Español de Arte, 243, 1988, págs. 271-289. 
La importancia del uso de los grabados es mucho mayor por cuanto no influyeron solamente en artistas de segunda fila sino que los usaron personalidades como Rafael ${ }^{3}$ o, en España, Fernando Gallego ${ }^{4}$.

El uso de los grabados fue una práctica generalizada. Eran colecciones que formaban parte del taller de los artistas como otro instrumento de trabajo más y muchos documentos muestran el valor de estas estampas al dejarlas sus dueños a otras personas como una donación en reconocimiento de la amistad o de los servicios prestados. Alejo Fernández, en su testamento de 25 de agosto de 1523, da libertad a su esclavo Juan de Guejar y le deja tres docenas de muestras de dibujos a su elección ${ }^{5}$. Villegas Marmolejo, en su testamento de 6 de diciembre de 1596, deja a Alonso Rodríguez, que tenía en su casa y a su servicio, los aperos de pintar y todos los moldes y modelos que en su casa se hallasen ${ }^{6}$.

El mismo Francisco Pacheco se muestra partidario de imitar del natural rostro y manos pero de hacer el resto del cuerpo a base de estampas, modelos de estatuas antiguas y de los excelentes perfiles de Durero.

Estos grabados divulgaron tipos y composición de escenas, fondos arquitectónicos y elementos decorativos. Unas veces los artistas los copiaron de forma íntegra y en la obra resultante es fácil rastrear su origen pero con más frecuencia sólo se aprovechaban parcialmente, de forma que es más difícil detectar su procedencia. Los fondos de los cuadros de Sturmio reflejan las ruinas que su compatriota Maarten van Heemskerck dibujó y grabó durante su estancia en Roma ${ }^{7}$. No era inusual combinar en una misma obra elementos extraídos de grabados diferentes.

Estos recetarios extendieron fórmulas extrañas a nuestro país llenándose, principalmente la pintura y la miniatura, de personajes ataviados a la moda centroeuropea o de fondos arquitectónicos del mismo origen, extraídos de grabados de Shongauer o Duero. Si el aporte alemán fue básico a la hora de componer o de que se colaran aquí vestidos y arquitecturas exóticas, Italia lo fue en los repertorios decorativos del grutesco, de cuyos temas se llenó España en todas las vertientes del arte. Los motivos se repitieron en piedra, metal, barro vidriado y madera, además de en pergamino.

Ya en el siglo XVI, en el que siguen estando plenamente vigentes los grabados de Shongauer, van a ser Durero, los grabadores italianos y, en menor medida, los centroeuropeos, que copiaron sus repertorios, los que más van a influir en los miniaturistas, pintores y escribanos que realizaron las historias, las letras miniadas y las orlas de los libros de coro de la Catedral de Sevilla.

Un pintor de la categoría de Alejo Fernández, que está trabajando en distintas labores para la Catedral de Sevilla desde 1508, pudo inspirarse para componer la Anunciación del libro de coro $51^{8}$, folio 53, en un grabado, probablemente milanés de hacia 1480 . Grabado y miniatura coinciden en la posición del ángel y, en menor medida, en la de la Virgen, en el pórtico y en los rayos de luz que llegan hasta ella. Quizás se apreciaría más el parecido de no ser porque a la miniatura le ha sido superpuesta una A, para adaptarloa al texto actual, que oculta seguramente la figura de Dios Padre, que aparece en el grabado, de la que salen los rayos tal y como se ve en otra Anunciación de Alejo Fernández que se encuentra en el Museo Provincial de Bellas Artes de Sevilla.

\footnotetext{
3 Angulo Íñiguez, D., «Martín Shongauer...», Op. cit., pág. 175.

${ }^{4}$ Angulo Íñiguez, D., «Gallego y Shongauer...», Op. cit.

${ }^{5}$ Muro Orejón, A., Documentos para la Historia del Arte en Andalucía, VIII, Sevilla, 1935, pág. 20.

${ }^{6}$ Gestoso y Pérez, J., Ensayo de un diccionario de los artífices que florecieron en Sevilla desde el siglo xIII al XVIII inclusive, Sevilla, 1989-1908, I, pág. 120.

${ }^{7}$ Martínez Burgos, P., «Los tópicos del paisaje en la pintura española del siglo XvI», Fragmentos, Madrid, 1986, pág. 76.

${ }^{8}$ In festo Sancte Marie ad Nives, año 1514.
} 


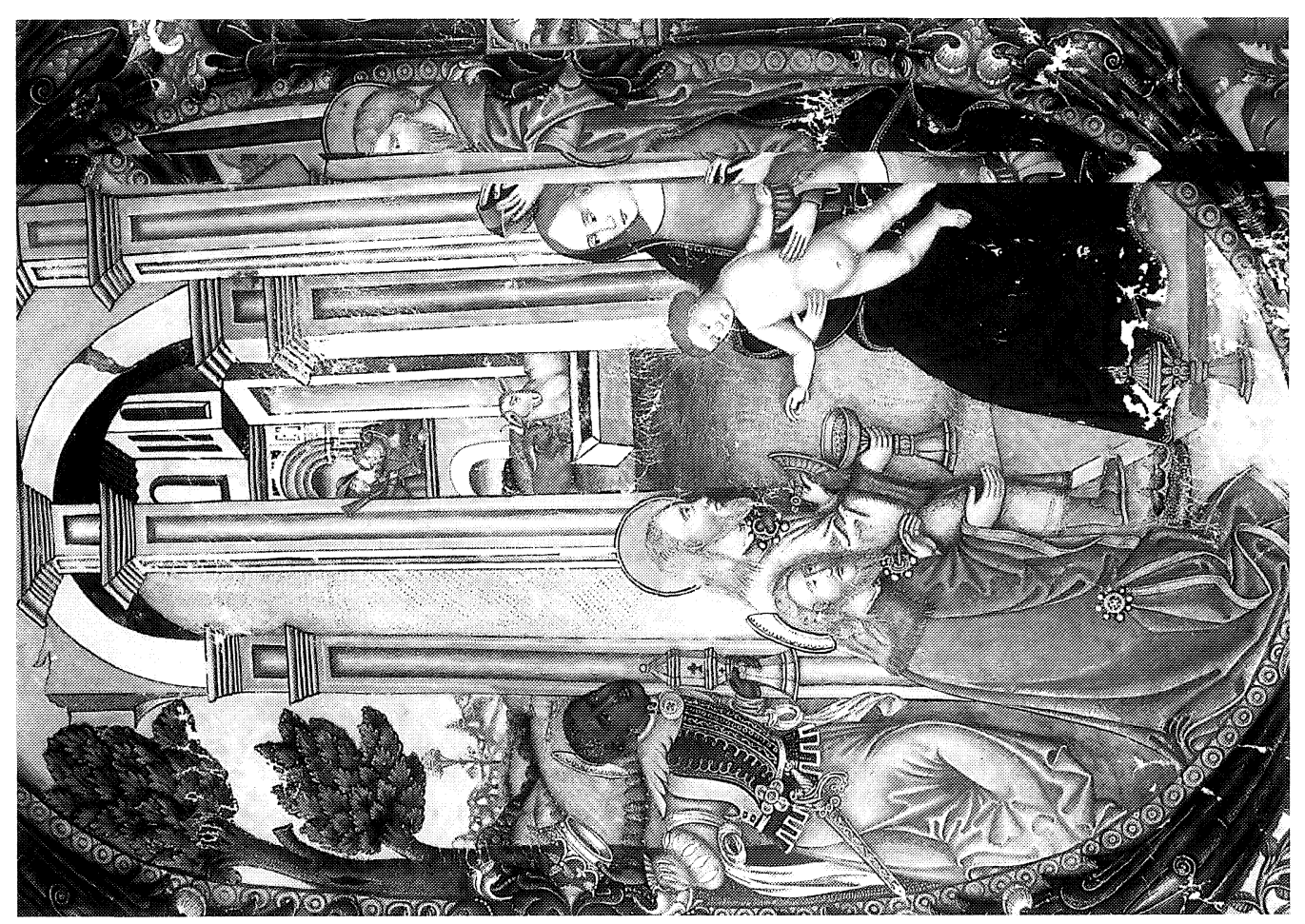

n

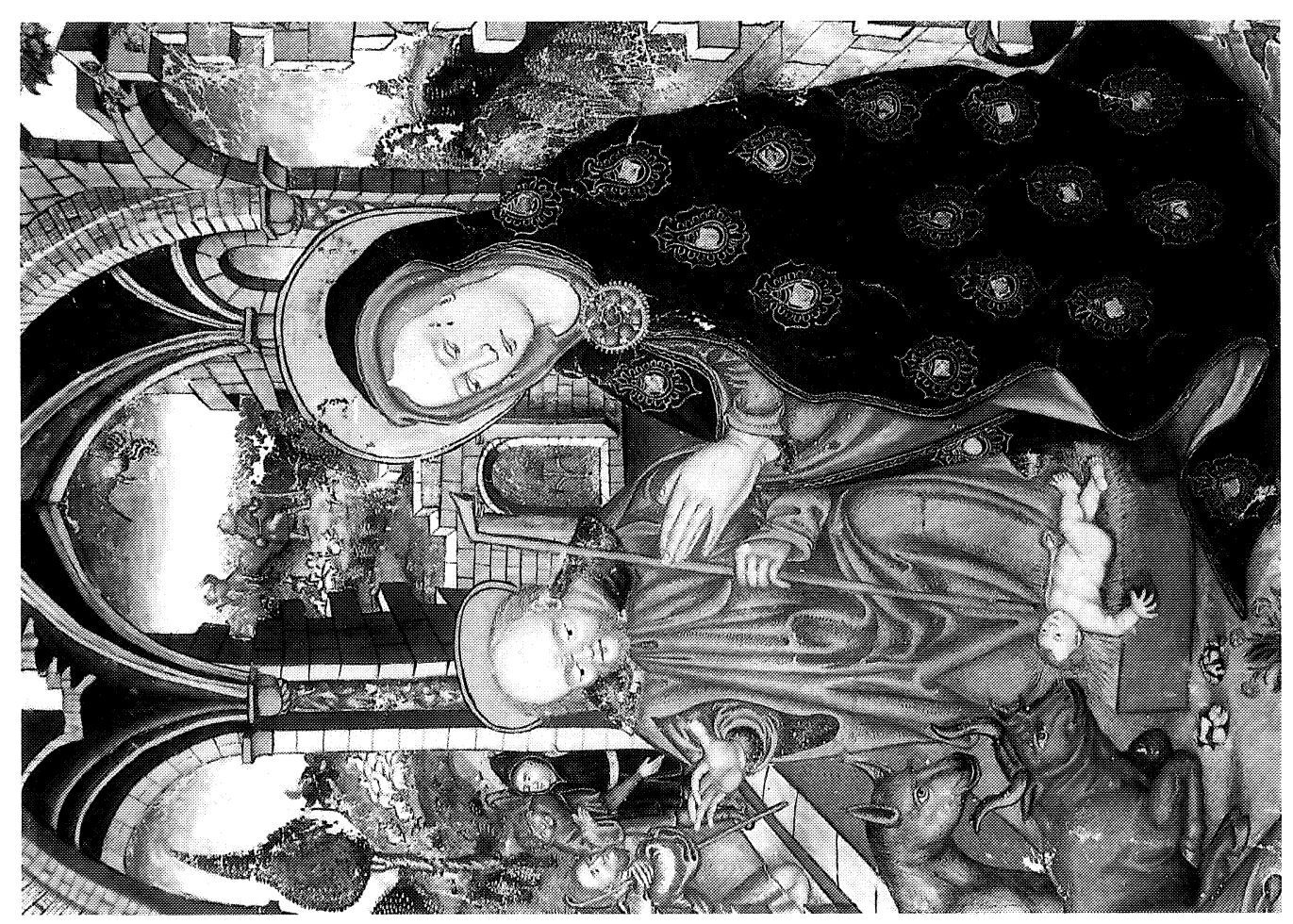

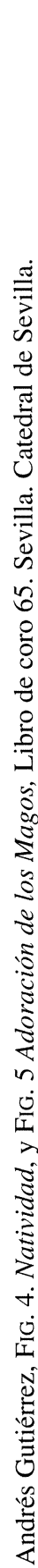


Andrés Gutiérrez, un miniaturista que trabaja para la catedral durante el primer tercio del siglo XVI, se basa para algunas de sus historias en grabados de Shongauer y Durero. La Natividad, que aparece en el libro de coro $65^{9}$, folio 1 vuelto (Fig. 4) se inspira en un grabado de Shongauer al que otro de Nicoletto da Modena sigue en el grupo central y en la Adoración de los Pastores. Aunque en la miniatura la escena central está invertida respecto al grabado, son similares la construcción gótica, que en el grabado de Nicoletto da Modena se vuelve renacentistas, el grupo de los pastores que aparece por el vano lateral y la diminuta Anunciación a los Pastores que se ve al fondo. Lacarra Ducay pone este mismo grabado de Schongauer, de hacia 1480, en relación con un Nacimiento del Santuario de la Peña de Ágreda ${ }^{10}$. El desconocido pintor ha seguido aquí únicamente las figuras de la Virgen, el Niño y San José olvidándose del escenario, donde se alojan los personajes, que tan fielmente sigue Andrés Gutiérrez.

En el folio 15 vuelto del mismo libro 65 hay una Adoración de los Magos (Fig. 5), también de Andrés Gutiérrez, de la que el grupo formado por San José, la Virgen, el Niño y el Rey Mago arrodillado delante de él está inspirado en un grabado de Durero así como los pastores que aparecen por el vano de la construcción.

En el folio 26 vuelto del mismo libro de coro aparece la Resurrección, también de este miniaturista (Fig. 6). Cristo, de pie sobre el sepulcro, se cubre con manto rojo que no oculta sus llagas y lleva en su mano izquierda la cruz estandarte. En los cuatro lados del sepulcro otros tantos soldados están «como muertos». Toda la escena está inspirada en un grabado de Girolamo Moceto (Fig. 7) del que Andrés Gutiérrez copia actitudes de los personajes, corazas, cascos, armas y paisaje, Gólgota incluido. Sólo la aureola de Cristo, que agrega un toque de divinidad, y la sangre que chorrea de sus manos, pies y costado, que lo dan de dramatismo, aportan algo diferente a esta escena. En este caso el grabado seguido por el miniaturista procede de Italia cuya influencia ha sido mucho menos estudiada que la Schongauer.

En el folio 26 vuelto del libro de coro $33^{11}$, Andrés Gutiérrez hace una Anunciación para la que se inspira en un grabado de Durero con el que coincide en la distribución de los cuatro personajes, Dios Padre, Espíritu Santo, María y el Arcángel, en el que copia exactamente igual la posición de las piernas y los pies y el movimiento de la túnica y el pelo. También sigue a Durero en la arquitectura, distribuyendo igual los vanos e interpretando la balaustrada y el dosel que aparece detrás de la Virgen.

En el folio 47 vuelto del mismo libro 33 (Fig. 8) el miniaturista ha representado el encuentro de San Joaquín y Santa Ana ante la Puerta Dorada y, en un plano más alto, una escena anterior en el tiempo, a San Joaquín en el campo recibiendo de rodillas la visita de San Gabriel que le anuncia que su mujer Ana tendrá una hija de la que nacerá el Mesías. Esta última escena copia fielmente un grabado de Durero. Las mismas figuras colocadas en la misma posición, con las mismas vestiduras y accesorios pues llega, incluso, a poner en la cintura del pastor que levanta las manos una gaita. Debajo de esta escena, separada de ella por la muralla de Jerusalén, la miniatura representa la del abrazo de San Joaquín y Santa Ana. Toda ella ha sido copiada de otro grabado de Durero de 1504 (Fig. 9) del que se ha reproducido exactamente el grupo de personajes masculinos que están junto a San Joaquín, con sus vestiduras y complementos, bolsas, puñales, sombreros, las figuras de los dos esposos y parecido escenario arquitectónico del fondo.

La adscripción a lo nórdico, que se refleja en múltiples aspectos de la obra de Andrés Gutiérrez, se ve reforzada por el uso de modelos de Shongauer o Durero para sus historias pero ya empieza a preciarse en ella, aunque débilmente, la influencia de la corriente artística proce-

\footnotetext{
${ }^{9}$ In Nativitate Domini, años 1529-1530.

${ }^{10}$ Lacarra Ducay, M. C., «Influencia de Martín Shongauer...», Op. cit., pág. 22.

$"$ In festo Assumptionis Beate Marie Virginis, años 1521-1523.
} 

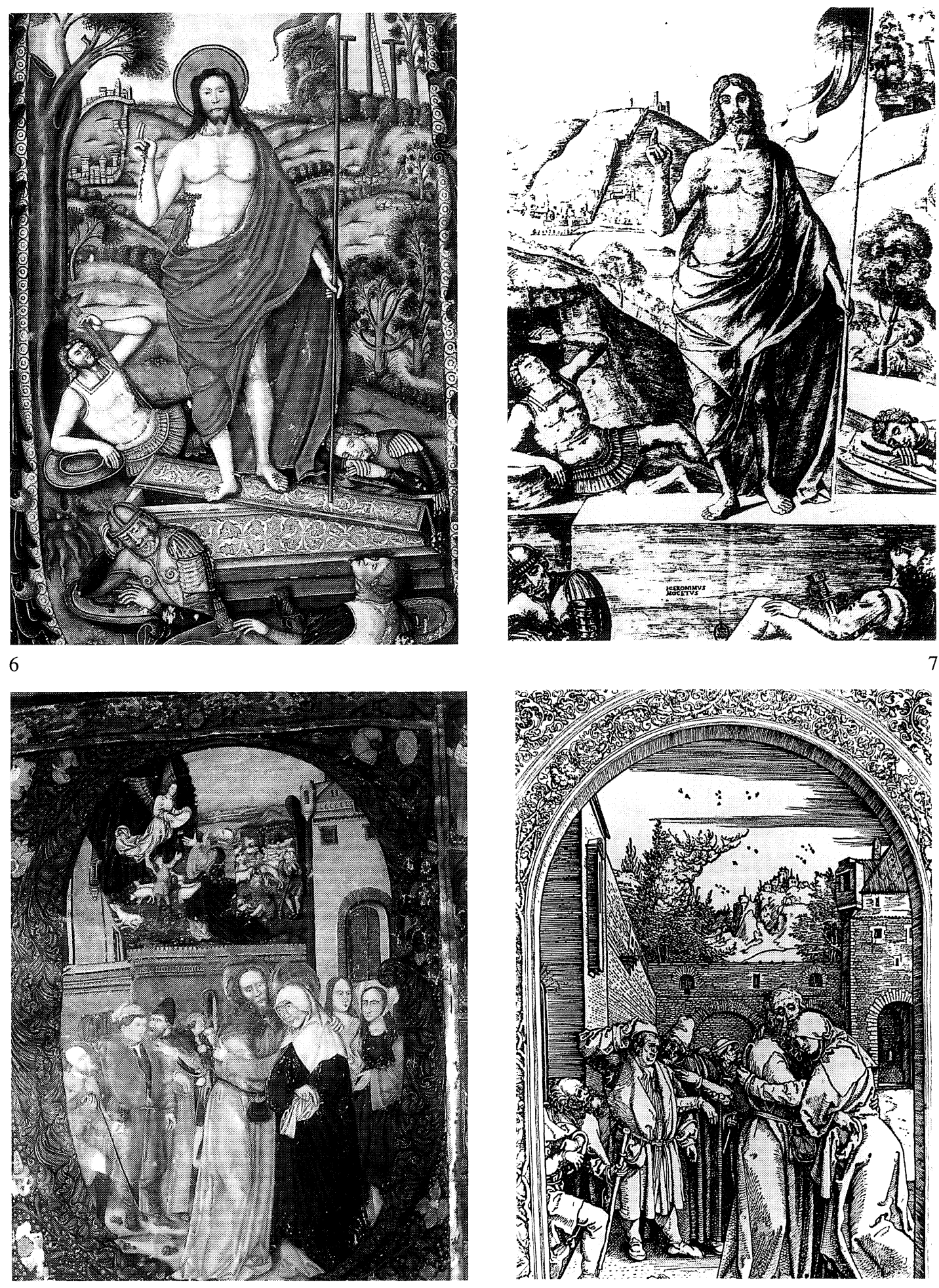

8

Fig. 6. Andrés Gutiérrez, Resurrección, Libro de coro 65. Sevilla. Catedral.

FIG. 7. Girolamo Moceto, Resurrección.

FIG. 8. Andrés Gutiérrez, Abrazo de San Joaquín y Santa Ana, Libro de coro 33. Sevilla. Catedral.

Fig. 9. Durero, Abrazo de San Joaquín y Santa Ana. 
dente de Italia que queda aún más de manifiesto con el uso para una de sus miniaturas de un grabado de Girolamo Moceto.

Andrés Ramírez, un pintor que está trabajando como iluminador en los libros de coro de la Catedral de Sevilla durante el segundo tercio del siglo XVI, va a seguir, para realizar algunas de sus miniaturas, grabados de Durero. En el folio 1 vuelto del libro de coro $8^{12}$ aparece una historia que representa la Presentación de María en el Templo. La Niña asciende los escalones en dirección al Sumo Sacerdote, que la espera arriba, sin mirar a sus padres que han quedado al pie de la escalera (Fig. 10). La escena ha sido copiada de un grabado de Durero (Fig. 11): el escenario arquitectónico del que se ha reproducido hasta el palio colocado en el pórtico del templo, la posición de la Virgen respecto a la columna, San Joaquín que sostiene en sus manos el mismo sombrero que en el grabado, Santa Ana y el grupo del Sumo Sacerdote y sus acompañantes. Andrés Ramírez ha simplificado la historia eliminando la escena popular del primer término y algún personaje del fondo.

En el folio 6 vuelto del libro de coro $41^{13}$ el mismo miniaturista ha representado a San Marcos sentado en su escritorio trabajando (Fig. 12). Tanto él como el león alado se encuentran en un interior donde se ha colocado todo tipo de instrumentos de un taller de escritura. La historia reproduce el grabado de Durero que representa a San Jerónimo escribiendo (Fig. 13). Ha mantenido exactamente los mismos elementos: dos ventanas con cristaleras, las mismas repisas y, sobre ellas, los mismos objetos, el mismo tipo de techo y parecida mesa. Ha variado respecto al grabado original, la silla, que ha convertido en una jamuga hispánica, la calavera, el sombrero cardenalicio, un perro que dormía delante y poco más. Pese a ello la miniatura es prácticamente un calco del grabado de Durero: el mismo atril sobre el que escribe el santo, el mismo león con el rabo entre las patas, aunque el de San Marcos exigía alas, y hasta el mismo reloj de arena que, en este caso, está sobre la mesa.

Los elementos que aparecen en las orlas de Andrés Ramírez, putti, sirenas, bucráneos, flameros, guirnaldas o cornucopias, están, en buena medida, extraídos de los grabados que, para entonces están llegando de Italia e incluso de los reproducidos en los libros impresos como el Libro de la doctrina cristiana de Gutierre González ${ }^{14}$. En algunos casos no solamente sigue de cerca los modelos sino que llega a imitar a la perfección sus líneas como ocurre con la orla del grabado de Anatomía del cuerpo humano realizado por Juan Jofre ${ }^{15}$. Son dos ejemplos de libros publicados por los años treinta que divulgan motivos procedentes de Italia. Ninguno de los temas que son definitorios del estilo de Andrés Ramírez es original. De todos ellos existen muchos modelos difundidos por los grabados: la figura femenina con la parte inferior del cuerpo como de rana nos la muestra un grabado de Nicoletto da Modena del tercer decenio del siglo XVI, el tocado femenino con nudos en las sienes se ve en otro de René Boyvin del quinto decenio, las cestas tejidas en diagonal aparecen, además de en el anteriormente citado, en un grabado de Augustin Hischrogel de 1543, los delfines de pico retorcido en otro del Maestro Italiano con el Dado de 1532. Si Andrés Ramírez se inspiró directamente de estas fuentes para la creación de su repertorio o incorporó algunos de estos temas de los que su padre el pintor Juan Ramírez hizo en los libros de coro de la Catedral de Granada es algo difícil de averiguar.

Diego Dorta, el escribano que trabajó para la Catedral de Sevilla desde 1543 hasta 1581, compuso sus historias, a veces, siguiendo modelos de Shongauer o Durero. En el folio 1 vuelto del libro de coro $67^{16}$ representa a Santiago Matamoros, aspecto esencialmente hispano de la

${ }^{12}$ In festivitate Anuntiatione, años 1535-1537.

13 Fiesta de San Felipe y Santiago e invención de la Santa Cruz, años 1535-1537.

${ }^{14}$ Cromberger, Sevilla, 1532.

${ }^{15}$ En la obra Libro o práctica de cirugía del muy famoso y experto Doctor Juan de Vigo, Valencia, 1537.

${ }^{16}$ Fiesta de Santiago, años 1561-1564. 


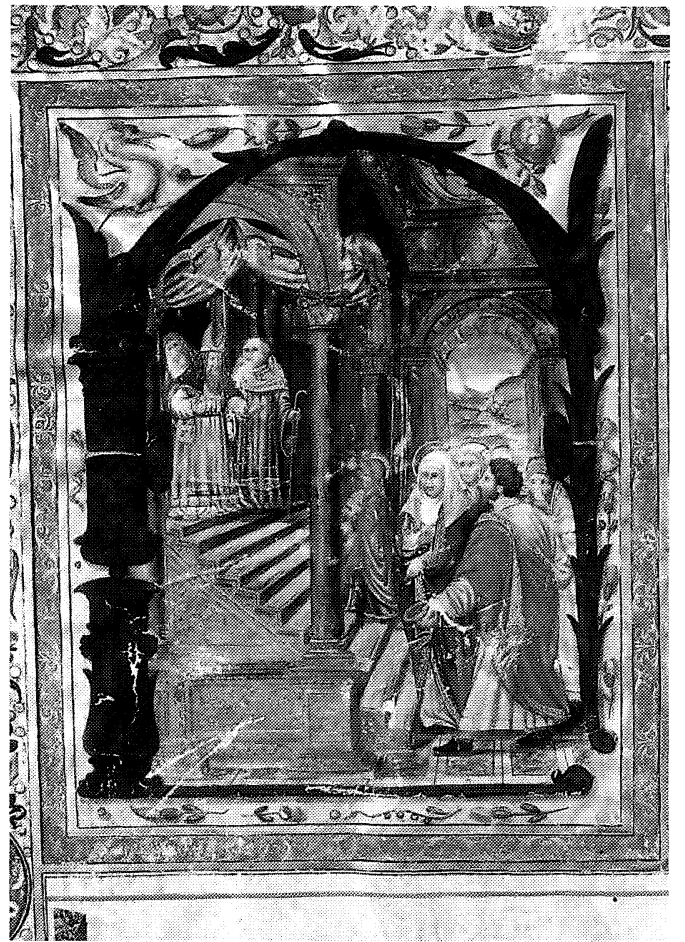

10

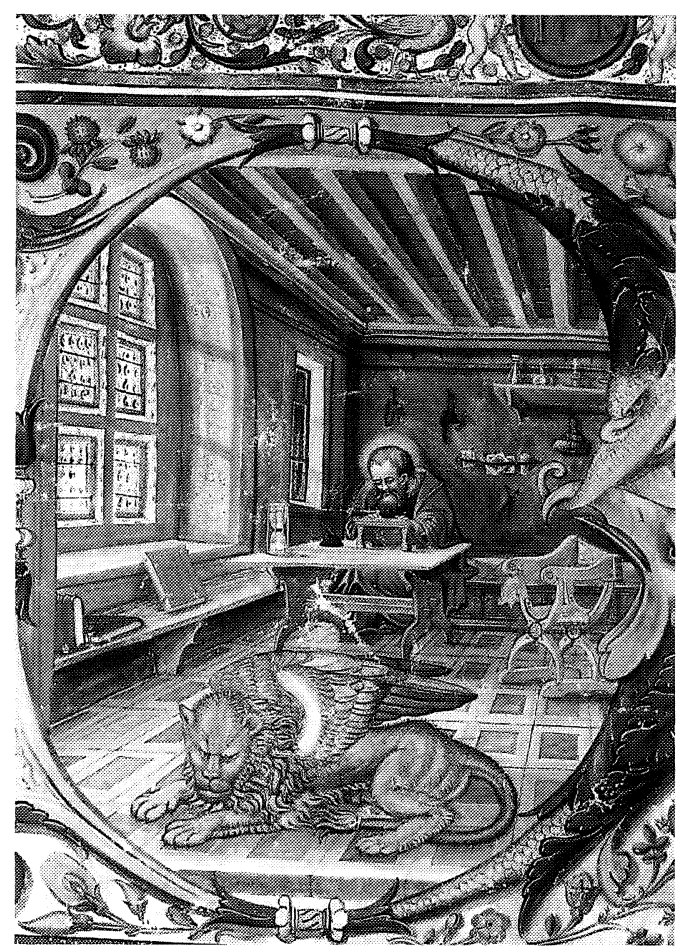

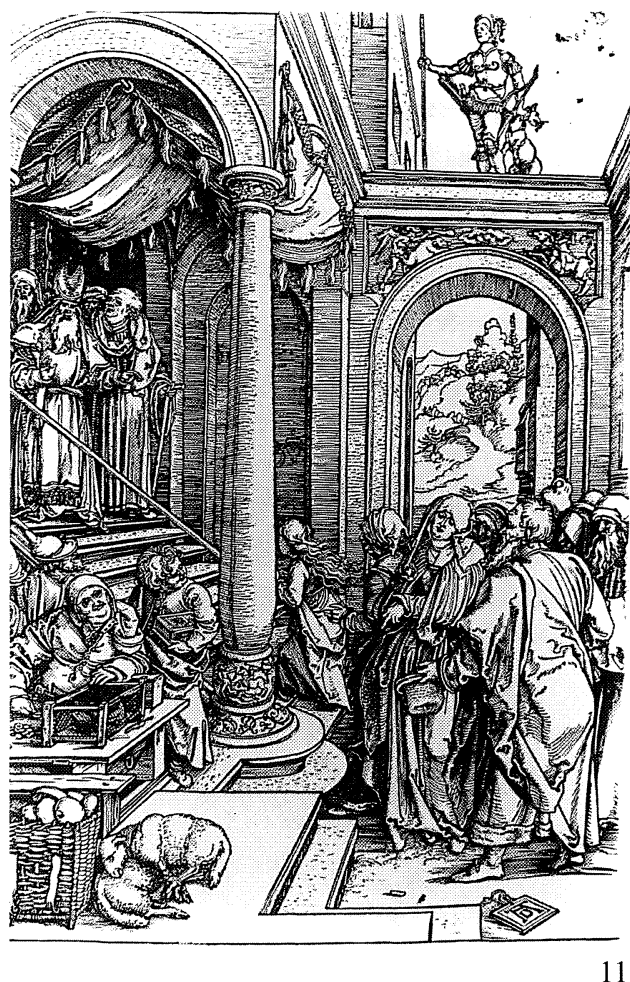

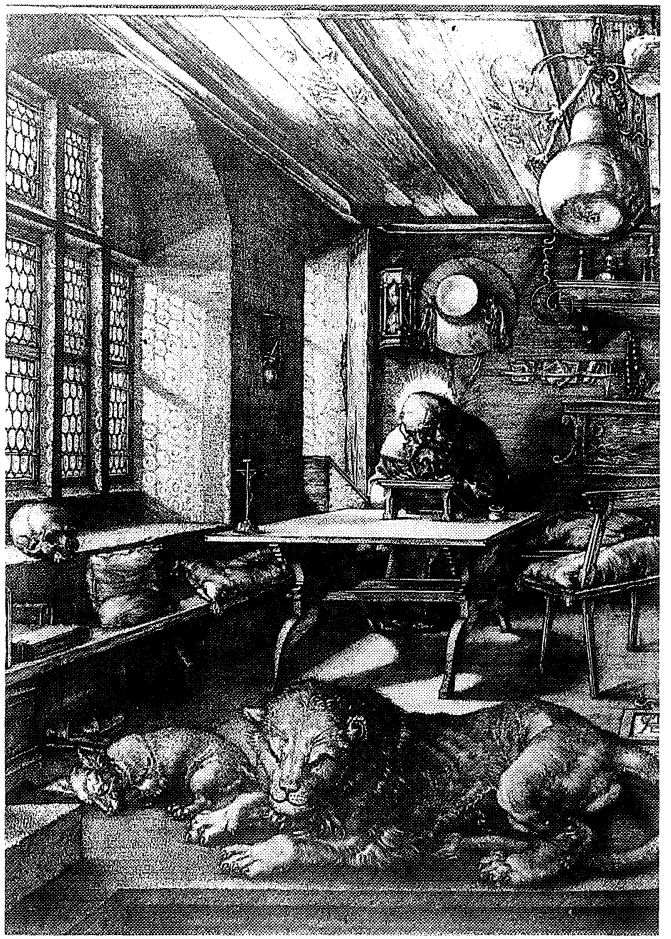

13

Fig. 10. Andrés Gutiérrez, Presentación de María en el Templo, Libro de coro 8, Sevilla. Catedral.

FIG. 11. Durero, Presentación de María en el Templo.

FIG. 12. Andrés Gutiérrez, San Marcos, Libro de coro 41, Sevilla. Catedral.

FIG. 13. Durero, San Jerónimo. 
iconografía del apóstol que lo muestra como paladín de la lucha contra el islam. Diego Dorta no se inspiró para realizar esta miniatura en los múltiples ejemplos que le mostraba el arte español sino que siguió un grabado de Shongauer de hacia 1470 que fue el que difundió esta faceta guerrera de Santiago por Europa. En ambos casos el caballo, que avanza a gran velocidad, lo que se denota por el movimiento del manto y el pelo del santo, ha arrollado al ejército musulmán. Pese a que Diego Dorta introduce algunas variantes en la miniatura respecto al grabado no puede quedar duda de que se basó en él para componer la historia puesto que no es el único caso en que usa grabados de Shongauer. Este grabado también fue imitado en Europa por los vidrieros franceses y por el autor de una miniatura del Breviario Grimani, manuscrito flamenco de la Biblioteca de San Marcos de Venecia ${ }^{17}$.

Diego Dorta representa el Bautismo de Cristo en un óvalo incluido en la orla que rodea el folio 1 vuelto del libro de coro $64^{18}$ en el que la historia principal se dedica a San Juan Bautista. La composición de esta escena la ha realizado el autor basándose en el grabado de Shongauer del mismo tema aunque ha invertido la colocación de las figuras. Efectivamente Cristo está de pie en la corriente del arroyo, muy encajado en el terreno. Difieren fundamentalmente el hecho de que Dorta no haya induido a Dios Padre que en el grabado está sobre el Espíritu Santo formado con Cristo una Trinidad vertical y el pelo corto de San Juan y el ángel, «a la romana». Otros detalles han sido ligeramente alterados, como las manos de Cristo o de San Juan, pero sin que lleguen a afectar a la composición de la obra.

En las orlas que realiza Diego Dorta, en ordenación de candelieri siempre, aparecen cartelas, cestas con frutas, paños y perlas colgantes, dragones, putti, seres híbridos... Todos estos elementos se encuentran repetidos en los grabados de la época. En el de Nicoletto da Modena de hacia 1510, que se reprodujo íntegramente en el panel del ángulo inferior derecho de la portada de la Universidad de Salamanca ${ }^{19}$, se encuentran todos los elementos que emplea Dorta y, desde luego, su sentido de la ordenación: esfinges de sereno aspecto, cartelas, máscaras, roleos que se enroscan a un lado y otro del eje y en cuyo centro hay una especie de flor como sombrilla, bucráneos... Las exuberantes orlas que emplea Diego dorta también están relacionadas con la decoración de muchos libros impresos de la época. Esta relación llega a ser identidad en el Compendio de los estatutos desta Santa Yglesia Metropolitana de Burgos ${ }^{20}$, en De uso et consuetudine de Pedro de Salazar ${ }^{21}$ o en In Legem Regioni Toleti Conditam... de Luis Mejía ${ }^{22}$. La fecha tardía de estos libros descarta la posibilidad de que Diego Dorta se inspirase en ellos para crear su repertorio de temas decorativos pero éstos ya existían a fines de la primera mitad del siglo XVI cuando el grabador aragonés Diego realiza en 1548 los Anales de la corona de Aragón ${ }^{23}$.

Los ejemplos citados demuestran que los iluminadores de los libros de coro de la Catedral de Sevilla se inspiraron para algunas de sus historias en grabados de Shongauer y Durero y, en menor medida, en italianos como Girolamo Moceto. Además de estas historias en las que con toda claridad se ve el modelo del que proceden, multitud de elementos decorativos de las orlas han sido extraídos de los grabados del momento. Para este caso priman los procedentes de Italia, los de Nicoletto da Modena o del Maestro italiano con el Dado aunque tampoco se pueden descartar los de los grabadores europeos Augustin Hirschrogel, René Boyvin o Hans Sebald Beham. Los miniaturistas conocieron estos grabados en los que se encuentra todo el repertorio

${ }^{17}$ Mâle, Emile, Les Saints compagnons du Christ, París, 1958, pág. 151.

18 In festo Sancti Johannis Baptiste, año 1565.

19 Sebastián López, S., «Las fuentes inspiradoras de los grutescos del plateresco», Príncipe de Viana, XVII, 1966.

${ }^{20} 1576$.

21 René Rabut, Granada, 1579.

22 Alonso García Escribano, Sevilla, 1568

${ }^{23}$ Zaragoza, 1562. 
usado por ellos: delfines, grifos y otros seres míticos, putti o angelitos sosteniendo un tondo, bustos de emperadores y otros elementos decorativos, además de ropas y tocados.

Los fondos de sus historias han sido también con frecuencia extraidos de los grabados. A veces son escenarios urbanos de ciudades claramente centroeuropeas como la que Andrés Ramírez representa en la miniatura de San José con el Niño de la mano del folio 1 vuelto del libro de coro $40^{24}$. Otras veces son escenarios arquitectónicos clásicos como la columnata ante la que Diego Dorta sitúa la historia de la Circuncisión, del folio 7 vuelto del mismo libro, basado quizás en el grabado italiano atribuido a Bramante.

Los miniaturistas copiaron de los grabados temas o figuras aisladas que luego combinaron a su manera haciéndolos en muchos casos irreconocibles. No es éste el caso de la mujer de peinado, perfil y vestido totalmente clásicos, que está en primer plano en la historia de la Circuncisión del folio 7 vuelto del libro de coro 40 y que no es más que la adaptación que hace Diego Dorta de la mujer de espaldas que aparece en la Transfiguración de Rafael cuya obra debió conocer a través de los grabados.

Temas como el del pequeño jinete de la orla de la página 1 del libro de coro $85^{25}$ no hace más que repetir un tipo usual en los libros impresos ${ }^{26}$. Todos deben derivar de un modelo común pues las coincidencias son muchas: miran a la derecha, están de perfil y el caballo en corbeta.

Los grabados tuvieron una gran importancia para los miniaturistas, pintores y escribanos que indistintamente iluminaron los libros de coro del siglo XVI de la Catedral de Sevilla pues gran parte de sus temas están extraídos de ellos pero además porque su influencia se prolongó durante mucho tiempo. La de Shongauer llegó al menos hasta 1565, año en que Diego Dorta está haciendo la historia del Bautismo de Cristo, es decir, hasta 100 años después de que empezara la producción artística del grabador. La influencia de los grabados de Durero se prolongó aún más pues todavía a principios del siglo XVII el pintor Francisco Pacheco recomienda su uso.

En los ejemplos expuestos se aprecia cómo se ha empleado el grabado de muy distinta forma para componer las miniaturas. En unos casos el aprovechamiento ha sido íntegro como en el de las historias de la Resurrección y de San Marcos que siguen fielmente grabados de Girolamo Moceto y Durero respectivamente. En otros se han eliminado figuras accesorias como en la historia de la Presentación en el Templo que sigue un grabado de Durero. No faltan los ejemplos en los que se reproduce el grabado invertido como en el caso de las historias de la Natividad y del Baustismo de Cristo que siguen sendos grabados de Shongauer e incluso aquel en donde se han sumado dos grabados, ambos de Durero, para componer la historia del encuentro de San Joaquín y Santa Ana ante la Puerta Dorada. Pese a la variedad, todos estos casos se parecen en que el original es fácilmente reconocible a través de la obra resultante pero cuando los grabados inspiradores no representan historias sino elementos decorativos, cuando están muy repetidos en distintos grabados o cuando estos elementos decorativos se usan aislados no se puede asegurar con absoluta certeza la fuente que ha usado el miniaturista para su inspiración.

En los libros de coro de la Catedral de Sevilla del siglo XvI la influencia de los grabados fue abundante, variada, respecto a la distinta forma en que se usaron, de distinta procedencia y prolongada.

Rosario MARCHENA HIDALGO

Universidad de Sevilla

\footnotetext{
${ }^{24}$ Oficio de Navidad y Circuncisión, años 1543-1558

${ }^{25}$ In natalittis plurimorum martirum extra tempus paschale, años 1561-1567.

${ }^{26}$ Aparecen estas representaciones en:

Fernán Pérez de Guzmán, Crónica del Serenísimo rey Don Juan II, Arnao Guillén de Brócar, Logroño, 1517.

Mateo María Boiardo, Orlando Innamorato, Nicolo di Aristotile di Ferrara, Venecia, ......
} 